\title{
Teaching To Think: Applying The Socratic Method Outside The Law School Setting
}

Evan Peterson, University of Detroit Mercy, USA

\begin{abstract}
An active learning process has the potential to provide educational benefits above-and-beyond what they might receive from more traditional, passive approaches. The Socratic Method is a unique approach to passive learning that facilitates critical thinking, open-mindedness, and teamwork. By imposing a series of guided questions to students, an instructor can challenge students to think for themselves, learn from their mistakes, and give them the necessary tools they will need to assess situations they will encounter in both their professional and personal lives.
\end{abstract}

Keywords: Active learning, Socratic Method, critical thinking

\section{INTRODUCTION}

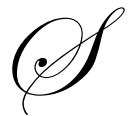

cholarship related to the vast array of classroom teaching techniques abounds in the realm of academia. While each of the various instructional styles possesses its own unique blend of favorable and unfavorable traits, each is utilized in one form or another to improve the value of the student learning experience. The historical methodology and framework for teaching a typical college course continues to evolve as a result of sociopolitical changes, advancements in technology, and an ever widening and diverse student demographic.

The breadth and depth of learning in all matters of human knowledge continues to grow at an exponential rate. As such, one needs to ask whether it is possible for a college course to impart enough information on any subject to do that subject justice. Courses on subjects from history and economics to business and biology are now only able to skim the surface of available knowledge on the topics they cover. In light of such developments, the argument can be made that the educational needs of students may be better served by providing them with the tools to examine and analyze any subject they may come across, rather than cementing into their heads an array of facts that may be subject to change. While background knowledge on a subject is naturally a prerequisite for such analysis, courses should lend greater focus to a analytical, active learning approach.

\section{ACTIVE LEARNING AND THE SOCRATIC METHOD}

As noted by Pintrich, McKeachie and Lin (1987) the cultivation of an inquisitive mentality is more important than the specific information that students learn in the classroom. If so, then quite naturally the method of instruction must allow for the promotion of active rather than passive student participation (Ferguson 1986; Phoenix 1987). ${ }^{1}$ It has been suggested that active and engaging learning techniques produce better results than more passive, less engaging techniques. ${ }^{2}$ Despite this, the traditional lecture method focuses on content and knowledge acquisition with little concern for the critical thinking process. An investigational, learning atmosphere in the classroom can only be achieved by focusing on the learning process instead of focusing purely on the end result. ${ }^{3}$

The Socratic approach to teaching provides such an inquisitive and active approach to facilitating student learning. It is the predominant teaching process employed in most American law schools, but it has applications

\footnotetext{
${ }^{1}$ Overholser, J. "Socrates in the Classroom." College Teaching 40, 1, 14-20 (1992).

${ }^{2}$ Smith, H.W. "Comparative Evaluation of Three Teaching Methods of Quantitative Techniques: Traditional Lecture, Socratic

Dialogue, and Psi Format.” Journal of Experimental Education. 55, 3. 149-155 (1987).

3 "Socrates in the Classroom" at 14.
} 
outside the law school setting. The Socratic Method actively engages students in the learning process, ${ }^{4}$ utilizing guided questions in order to channel the thinking process of the student along a course defined by the instructor. ${ }^{5}$ The Socratic Method begins with asking an initial question, then posing further questions in response to student answers.

The process consists of a back and forth movement between proposals and counter proposals, in an effort to elicit more complete definitions from students in an effort to discover a universal idea. ${ }^{6}$ If student comments or answers are debatable or artificial, the Socratic line of questioning allows the instructor to ask guided questions so that students correct their own mistakes. In addition, it can aid in fruitfully expanding upon a student insight and integrating it into the case discussion, move an unorganized discussion ahead, and clarify confusing issues or concepts.

There are a number of things an instructor can do to facilitate a Socratic discussion: ${ }^{7}$

- $\quad$ Ask a student to provide instances or justifications for the position advocated

- Interject a counter-example in response to a student's position or point

- $\quad$ Ask whether anyone in the group agrees with the position advocated

- $\quad$ Suggest a parallel example

- $\quad$ Illuminate a specific concept or position using an analogy

- $\quad$ Play the role of devil's advocate to an articulated position

The instructor can use these techniques in the questioning process to redefine the concept which will lead to increasingly accurate elucidations by students. ${ }^{8}$ The purpose of the questioning is not to impart factual knowledge but to help the student think his or her way through a problem scenario or about a particular issue. ${ }^{9}$ The method behind the madness is to illuminate a specific concept in such a way that the concept or knowledge can then be effectively applied by the student to a virtually limitless range of possible situations. The desired result of this form of questioning is to prevent passive acceptance and memorization of facts and concepts and to challenge the student to think independently (Rocklin 1987). Robotic acceptance by students of information contained in class discussions does an injustice to the complexities of the issue at hand and to the intelligence of the student. It should be kept in mind that in order for the Socratic Method to be applied effectively, students must possess sufficient background information of the issues and knowledge of the topic in order to have meaningful participation.

The result of the process is that students gain a deeper understanding of the theory behind the idea (Chessick 1982; Seeskin 1987). The generalization reached through the Socratic Method has a number of benefits. First, a universal definition assists the student in discovering how to relate innovative theories to established methods. Second, precise questions allow students to relate past occurrences to current or future situations. Third, a universal conceptualization allows students to develop methodologies that translate to a vast assortment of situations that may be encountered. ${ }^{10}$ The feature that distinguishes Socratic questioning from other types is that it is a multifaceted, systematic and disciplined approach that centers on foundational principles, issues, or problems. ${ }^{11}$

\footnotetext{
4 “Comparative Evaluation of Three Teaching Methods of Quantitative Techniques: Traditional Lecture, Socratic Dialogue, and Psi Format" at 150.

5 "Socrates in the Classroom" at 14-15.

${ }^{6}$ Howard, G. "Socrates and Technology a New Millennium Conversation." International Journal of Instructional Media, Vol 33 (2006).

${ }^{7}$ Paul, R. and Elder, L. "Critical Thinking: The Art of Socratic Questioning, Part III.” Journal of Developmental Education 31, 3 34-35 (2008).

8 "Socrates in the Classroom" at 18.

9 "Socrates in the Classroom" at 15.

10 "Socrates in the Classroom" at 18.

${ }^{11}$ Paul, R. and Elder, L. "Critical Thinking: The Art of Socratic Questioning.” Journal of Developmental Education 31, $136-37$ (2007).
} 


\section{CRITICISMS OF THE SOCRATIC METHOD}

The effectiveness of the Socratic Method as an instructional methodology has been assailed on a number of fronts. First, it has been criticized as infantilizing, demeaning, sadistic and detrimental to positive values. ${ }^{12}$ It is said that even proponents of the Socratic Method realize that the method can be abused by instructors. In addition, various studies suggest the Socratic Method has a negative impact on women and minorities. ${ }^{13}$ The argument is also made that this form of teaching is culturally insensitive and inappropriate in light of an increasingly diverse and global student body. Furthermore, it has been criticized as a hindrance to students with different learning styles and an ineffective means of teaching any form of practical skills. ${ }^{14}$

While these criticisms have merit, it is important to remember that the abusive conduct touted as a serious drawback of the Socratic Method results from the abusive nature of the instructor, not the inherent nature of the Socratic style itself. ${ }^{15}$ While an instructor may display biases based on race or gender, criticize student comments, or conduct class in a demeaning manner, the possibility for these occurrences remains no matter what teaching style is employed. In addition, there is an assortment of accommodations that can be employed to neutralize the detrimental effects attributed to the Socratic Method. To counteract the possible reticence of an individual student or segment of students towards volunteering, an instructor could rely primarily on calling upon students. Obviously it would be up to the instructor to ensure that his or her questions are fielded appropriately among the students. For instance, the instructor might decide to alternate between calling upon male and females students, depending on the gender composition of the class. Furthermore, the instructor should be cognizant of the types of questions he or she is posing, to ensure an even distribution of questions with varying levels of difficulty to all students.

As with other teaching methods, it is vital that the Socratic questioning be conducted in an encouraging and open manner. Positive reinforcement should be given liberally when appropriate. This can be achieved by complimenting students on their well-thought answers and their insightful questions, and referring to such answers and questions later in the discussion if applicable. Student anxiety or trepidation of being put on the spot might be mitigated by allowing students to confer with a classmate when given a difficult question. ${ }^{16}$ Such a tactic has the added bonus of reinforcing the dynamic of teamwork that will be essential in the "real world." An instructor may also give the student a few moments to formulate an answer, possibly coming back to the student after a few moments. Finally, it is also important that the instructor explain the thought-process behind conducting class in such a manner, encourage student participation, and reassure them that the classroom is a place of learning and not a place of antagonism. ${ }^{17}$ An approach utilizing these various accommodations in the appropriate manner and context would allow for a reduction in the oppressive Socratic atmosphere while, at the same time, maintaining the intellectual inquiry that is the backbone of Socratic teaching. ${ }^{18}$

\section{BENEFITS OF THE SOCRATIC METHOD}

The purpose of this paper is not to suggest implementation of the Socratic Method as it exists in many American law schools. Instead, what is advocated for here is a less intimating version of the method that includes a modest amount of lecture and instruction but still stresses the fundamental principle of cultivating critical thinking through the active learning process of Socratic questioning.

It is important that the Socratic Method's critics not forget that its use advocated here is not intended to impart knowledge on any particular subject matter. For example, it is not advisable to use Socratic questioning to impart knowledge of historical events. However, it is extremely appropriate to use the Socratic Method as a means

\footnotetext{
${ }^{12}$ Vitiello, M. "Professor Kingsfield: The Most Misunderstood Character in Literature." 33 Hofstra Law Review 955,967 (2005).

${ }^{13}$ Garner, D. "Socratic Misogyny? Analyzing Feminist Criticisms of Socratic Teaching in Legal Education.” 2000 Brigham Young University Law Review 1597, 1598 (2000).

14 "Professor Kingsfield: The Most Misunderstood Character in Literature" at 970.

15 "Socratic Misogyny? Analyzing Feminist Criticisms of Socratic Teaching in Legal Education" at 1639-1640.

16 "Socratic Misogyny? Analyzing Feminist Criticisms of Socratic Teaching in Legal Education" at 1641-1642.

17 "Socratic Misogyny? Analyzing Feminist Criticisms of Socratic Teaching in Legal Education" at 1642-1644.

18 "Socratic Misogyny? Analyzing Feminist Criticisms of Socratic Teaching in Legal Education” at 1634.
} 
of looking at certain historical events and analyzing how they and their progeny have shaped the course of history. If the Socratic Method is, as it should be, viewed as a means of critically examining a particular subject, its applications can be extensive. Even in an applied mathematics or science course, calculation of a solution is often only the first step. The second step is to interpret the results of that calculation, to determine what that number means and examine how it fits into a real-world context.

The Case Method approach to problem solving employed in many business schools is similar to the Socratic approach. However, it has been suggested that the Case Method suffers from various drawbacks, such as being too time consuming and a poor means of teaching quantitative techniques. In addition, Case Method cases have been criticized as being self-contained, pre-packaged documents that describe an actor and a decision with predefined data upon which to base analysis and decision. However, as it has been argued, in the "real world" problems are rarely clear cut, complete, and possessing of reliable data. Further, it is suggested the Case Method fails to give sufficient weight to the role organizational politics often play in decision making. ${ }^{19}$ Furthermore, cases studied may be either too broad, too narrow, or not directly on point with issues discussed in class. With the Case Method there may be a tendency to accept all facts given in the case as true. Little or no critical analysis is given to them as presented. In addition, one may tend to focus only on the information presented, forgetting the possibility that there may be other pertinent information not contained in the case that could dramatically affect the final outcome.

Use of a more Socratic approach may help to reduce some of the drawbacks of using the Case Method. The Socratic method takes critical analysis to the next level, probes deeper into the factual scenario, not only looking at every presented fact and asking who, what, when, where and why, but also examining the situation in light of other pertinent factors that may have been overlooked by the available information. This reinforces the concept that rarely is one presented with a complete picture of a situation.

The Socratic Method doesn't rely on case materials for its existence. While it frequently employs cases to illustrate a point, these cases are merely a starting point to guide initial questioning. If a case merely touches on an issue the instructor desires to address, he or she can alter the facts to further challenge student thinking. Furthermore, the factual scenario of the case study need not be an extravagant production. While the ability to sift through mountains of available material on a subject and pick out key facts is an important skill, students need not be bombarded with an endless amount of appendix material containing financial statements, employment statistics, and company marketing plans. All they need is enough background information to have a meaningful discussion and conduct a thorough, well-thought out analysis.

While a certain level of background knowledge is essential to conducting a proper critical analysis, it is important to ensure excessive class time is not allocated to rehashing the same information students have read in their textbooks. The majority of the preparation should occur before class; the instructor need only clarify any gross confusion and paint the initial picture to begin the discussion. The goal is to give life to the material, not repeat it to the point of exhaustion. The purpose of class time is to bring other elements to the learning process that are not available to an individual studying the information alone in a dorm room: the experiences and comments of peers, guided questions by a learned instructor, and a competitive yet encouraging atmosphere that will get a student's adrenalin pumping and critical ideas flowing.

\section{CONCLUSION}

The active learning methodology facilitated by the Socratic Method provides students with an excellent means of judiciously analyzing a situation related to virtually any academic subject. By utilizing such a line of questioning, rather than imparting knowledge to students which they may passively accept, the richness of the academic experience is greatly enhanced. While such an approach need not be used in every situation, instructors should seriously consider working it into their classes in one form or another because of the rich benefits it can provide. When it is used, it may be tailored to fit the needs of the course, instructor, and students. Although the

\footnotetext{
${ }^{19}$ Heskett, J. "Is Case Method Instruction Due for an Overhaul?" (Jan. 4, 2009) at http://hbswk.hbs.edu/cgi-bin/print?id=6001.
} 
Socratic Method is not perfect in theory or practice, it can be a very effective means of not only encouraging student participation in the classroom, but also fostering the vital traits of open-mindedness and critical inquiry.

\section{AUTHOR INFORMATION}

Evan Peterson, JD, MBA has taught as an adjunct professor in the College of Business Administration at the University of Detroit Mercy. He is also published in the Journal of Business \& Economics Research, and his other areas of publication include scholarly articles on supply chain management, technology, decision making and innovative teaching methods. His current research interests focus on the effects of legal regulation on corporate culture, the regulatory framework surrounding securities law, and the regulation of the conduct of securities firms in light of the most recent scandals.

\section{REFERENCES}

1. Garner, D. "Socratic Misogyny? Analyzing Feminist Criticisms of Socratic Teaching in Legal Education." 2000 Brigham Young University Law Review 1597, 1598 (2000).

2. Heskett, J. “Is Case Method Instruction Due for an Overhaul?" (Jan. 4, 2009) at http://hbswk.hbs.edu/cgibin/print?id=6001.

3. Howard, G. "Socrates and Technology a New Millennium Conversation." International Journal of Instructional Media, Vol 33 (2006).

4. $\quad$ Overholser, J. "Socrates in the Classroom." College Teaching 40, 1, 14-20 (1992).

5. Paul, R. and Elder, L "Critical Thinking: The Art of Socratic Questioning, Part III.” Journal of Developmental Education 31, 3 34-35 (2008).

6. $\quad$ Paul, R. and Elder, L. "Critical Thinking: The Art of Socratic Questioning." Journal of Developmental Education 31, 1 36-37 (2007).

7. Smith, H.W. "Comparative Evaluation of Three Teaching Methods of Quantitative Techniques: Traditional Lecture, Socratic Dialogue, and Psi Format.” Journal of Experimental Education. 55, 3. 149155 (1987).

8. Vitiello, M. "Professor Kingsfield: The Most Misunderstood Character in Literature." 33 Hofstra Law Review 955, 967 (2005). 
NOTES 